Lawson suggested that a safe level should be well away from the level associated with the recent run of burning accidents, but not so high as to eliminate more types of fabric and flame retardant treatments than necessary. It was recommended that fabrics with a durable flame resistance rating of greater than 150 should be warranted as flameproof and identified as such. Most of the manufacturers of durable flame proofs are confident of being able to meet this standard, and many useful unproofed fabrics would be rogarded as being safe.

The discussion by members of the conference was particularly stimulating, and included contributions from Dr. J. B. Bull, who has been intimately concerned with surveys made by the Burns Unit of the Medical Research Council, and from Mrs. Jean Mann, M.P., Mrs. F. P. A. MeLaughlin, M.P., and Mr. Hervey Rhodes, M.P., all of whom are well known for their interest in the problems of safety and textiles.

The goneral conclusion from the conference was a unanimous agreement on the need for an intensified safety campaign at national level and for providing safe fabrics. Although many of the fabrics at present regarded as dangerous can be made safe by troatment with reagents such as tetrabishydroxymethyl phosphonium chloride, antimony oxide, and mixtures of antimony and titanium oxides, it was rocognized that a need still exists for cheaper durable treatments. Members of the conference, particularly the chemists and textile finishers, left greatly encouraged, knowing that the difficult problems with which they have to deal are sufficiently important to demand maximum effort and imagination.

C. S. WHEWELT

\section{THE ROCKEFELLER FOUNDATION}

$\mathrm{N}$ the Rockefeller Foundation annual report, 1956, I the President's review, reprinted with a summary of the Appropriations Account and Principal Fund and a list of appropriations made in 1956, notes that for the year the appropriations totalled $30,075,305$ dollars, the largest for any one year since the Founda. tion was established in 1913. Of this total, $5,963,605$ dollars were for the humanities, 5,501,100 dollars for biological and medical research, $4,877,400$ dollars for agriculture, 4,290,605 dollars for medical education and public health and 3,290,260 dollars for social sciences. For the fellowship programme, under which 458 individuals from 47 countries held fellowships in 1956, 2,025,000 dollars were appropriated.

In his review Dean Rusk stresses three features of the year's activities. First, noting that nineteen of the present eighty-one member States of the United Nations, with a population of more than 650 millions, have emerged as fully independent nations since the Second World War, he emphasizes that the officers and trustees of the Foundation believe that peace and orderly economic growth in the world during the next twenty-five years will be decisively influenced by what happens in these independent nations of Africa, the Middle East and Asia. Peace and stability will gain enormously if they establish constitutional systems with friendly and easy exchange with the rest of the world, increasingly productive economies, and educational systems which can train leaders in adequate numbers and educate their citizens for the responsibilities of their now societies. To enable the Foundation's ex- penditure on Latin America, Asia, the Middle East and Africa to be sharply increased without a large reduction of expenditure in the United States and Europe, the Trustees have decided to draw on capital funds for several years. During 1956 some 6 million dollars were allocated to the expanded programme, over and above the normal allocations to these areas from income.

Secondly, the President reviews at some length the Foundation's responsibilities in the nuclear age, commencing with its grant in 1940 toward the construction of a 184-in. cyclotron at the University of California, Berkeley. The report suggests that there are three main directions in which the resources of the Foundation can be usefully applied, taking into account the very large sums available from government and industry. The first is the public health aspects of nuclear energy, broadly conceived and for study of the effects of radiation on man. For the formulation of questions upon which further research is urgently noeded the Foundation has already made grants to the National Academy of Sciences totalling 275,000 dollars. The second is in the Foundation's traditional support of basic scientific research with the main emphasis upon the living processes. Here, the nine grants for research in genetics made during the year totalled 991,000 dollars, the largest, 350,000 dollars, being to the University of Indiana, while 260,000 dollars went to the University of Copenhagen, 61,000 dollars to the National Centre for Scientific Research, Paris, 50,000 dollars to the Institute for Human Genetics, Upsala, and 24,000 dollars to the London Hospital Medical School. A third type of study for which Foundation support is planned, on a selective basis, is that of the economic, legal and political problems of the nuclear age, with special reference to the increasingly complex issues of international relations, with which nuclear energy is now inextricably bound up. About a dozen grants have been made to young professors in universities throughout the United States studying a wide range of contemporary political problems. The Foundation also hopes to assist a few mature scholars to embark on, or to complete, significant research in this field, to encourage institutes to undertake objective studies of international political problems, to stimulate the growth of organized knowledge and theories of foreign policy, including the techniques and principles involved in its conduct.

The third aspect of the year's activities emphasized by Dean Rusk is the assistance given to Hungarian scientists, scholars and students. To this refugee problem the Foundation in late 1956 and early 1957 devoted more than 1,200,000 dollars, almost 700,000 dollars of which went to the institutions in Austria which bore the brunt.

In the field of medical education and public health considerable attention was paid to professional education, grants for which included 367,400 dollars to the Christian Medical College, Vellare; 299,750 dollars to King George's Medical College, Lucknow ; 273,300 dollars to Seth Gordhandas Sunderdas Medical College, Bombay ; 570,000 dollars to the University of the Andes, Bogotá; 215,000 dollars to the Recife Medical School, Brazil ; 290,000 dollars to the School of Medicine, Keio University, Tokyo ; and 100,000 dollars to the Department of Child Health, University of Ankara. A grant of 163,280 dollars was made to provide four years support for studies of population dynamies in Indian villages jointly by Harvard 
University and the Christian Medical College, Ludhiana, while one of 250,000 dollars to the Massachusetts Institute of Technology, for medical and biological research, was for the construction of a 1,000 kilowatt nuclear reactor at Boston, which would project a beam of nuclear rays into a therapy room underneath.

Some rather substantial grants of a general character made in 1956 were for the library at the international zoological station, Naples; for biological research at Amherst; for research in the natural sciences at the University of Mexico; and for biology, experimental medicine and surgery at Copenhagen. The largest of three grants for investiga. tion of ways of meeting the nutritional requirements of children, especially during the critical years after weaning, was to the National Research Council and is being administered in close co-operation with the global programme of the United Nations Children's Fund. About 1,250,000 dollars were appropriated for field studies of viruses and basic research in virology. This included aid to collaborating groups.

In 1956 a further co-operative agricultural programme was started at the Indian Agricultural Research Institute, New Delhi, the first interests of which will be to improve the corn, wheat and other cereal crops and broad questions of advanced agricultural training and research. Under the Mexican co-operative programme, more than 400 young Mexicans and some 85 other young scientists from Latin America and the United States have received training. During 1956, 204 individuals from 30 countries received fellowships, scholarships or other study and travel grants in agriculture. Besides its participation in various types of international exchange in this field, such as the conference of 50 lead. ing pathologists from Latin America, the United States and Canada on cereal rusts, the Foundation made numerous grants to institutions. These included 300,000 dollars to the College of Agriculture, University of Chile; 250,000 dollars to the College of Agriculture, University of the Philippines; and 200,000 dollars to the School of Agriculture, Universidade Rural de Minas Gerais, Brazil. A threeyear grant of 153,600 dollars was made to the Harvard Graduate School of Public Administration to assist a seminar offering advanced training in new methods of water conservation and management.

In the social sciences, a grant of 98,400 dollars to the Computer Centre, Massachusetts Institute of Technology, was for further exploration of the uses of an advanced high-speed digital computer in solving theoretical and applied problems in the social sciences. A grant of 150,000 dollars to Vanderbilt University was for its Institute of Research and Training in the Social Sciences ; of 114,000 dollars to Tulane University of Louisiana, for Latin American, legal and social studies ; of 96,000 dollars to Stanford University, for its Food Research Institute ; and of 50,000 dollars to the International Bank for Reconstruction and Development for its Economic Development Institute. The largest grant for international understanding in the United States in 1956 was on $\theta$ of 205,000 dollars over six years to the Harvard University Centre for Middle Eastern Studies, while 140,000 dollars went to the Federated Theological Faculty of the University of Chicago for interreligious studies. The American University of Beirut received 216,000 dollars in continued support of its Arab studies programme.

\section{ONTARIO RESEARCH FOUNDATION}

\section{REPORT FOR 1956}

$\mathrm{T}$ $\mathrm{HE}$ annual report of the Ontario Research Foundation for $1956^{*}$ includes, besides the report of the director of research, Dr. H. B. Speakman, the financial statement and lists of papers published during 1956, with details of professional and technical staff, advisory committees, scholarships and post. graduate grants in science, 1956-57. In the Depart. ment of Biochemistry, where work for the tanning industry increased, progress was made in a group project on the production of sole leather with increased resistance to wear. The oils and fats laboratory has been investigating the production of a spread for use on Army biscuits, manufactured if possible from Canadian raw materials. It has also been studying the autoxidation of methyl isolinoleate, linoleate and oleate, using the Warburg respirometer, and the separation by gas chromatography of the volatile substances produced during the deterioration in flavour of fats and oils. A study of the fermentation of cheese whey was completed.

In the Department of Chemistry progress was made both in the development of methods for separating and determining different constituents of waste sulphite liquor and in evaluating the lignin components as sources of tanning agents and dispersing agents. Work also continued on the production of organic polymers, and the Foundation is supporting the design and construction of an atmospheric X-ray spectrometer incorporating an electron gun. Application of improved techniques developed for the analysis of condensed phosphates in fundamental studies of phosphate glasses, solutions and crystalline compounds led to the conclusion that there is a remarkable similarity in the dependence of the molecular-weight distribution of the glassy phases on their cation to phosphorus ratio.

Studies of the mechanism of fatigue failure of metals advanced considerably, and it was shown that a strong magnetic field affects the fatigue strength of ferritic metals. Basic research in the X-ray laboratory was concerned mainly with X-ray spectrographic studies, and more time was given to an investigation of the initial stages of oxidation on a metal surface.

In the work on parasitic nematodes, a minute nematode, A proctella stoddardi, was recovered from a ruffed grouse, and is believed to account for one of the microfilariæe previously described as occurring in this bird. Low dosages of 'Daraprim' comparable to those effective against human malaria did not prevent infection from Leucocytozoon simondi developing in ducks, and particular attention was also paid to the relation between the time of infection and the prevalence of blood-sucking insects known to foed on ducks.

Work was commenced on the composition of the sand fraction from glacial tills and comparable waterlaid sands, while studies continued on the relation between variety and yield of soybeans. In textile research, the Sigma Unevonness Tester, previously developed, was used in a survey of worsted yarns produced in Canada, and to a limited extent in the United States and Europe.

* Ontario Research Foundation. Annual Report, 1956. Pp. 31. 